\title{
Администрирование социального обеспечения: некоторые тенденции и перспективы
}

\begin{abstract}
Аннотация.
Демографические и технологические изменения такие, как старение населения и цифровизация, оказывают глобальное влияние на социальную сферу и рынок труда. Трансформация традиционной модели занятости с расширением неформальных трудовых отношений и трудовой мобильности, а также сокращением налоговых (страховых) поступлений от трудовых контрактов определяют соответствующую трансформацию социального обеспечения и его администрирования. В тоже время электронные и интернет-технологии заменяют предоставление социальных услуг в бумажном формате с присутствием получателей таких услуг. Как ответ на эти вызовы для администрирования социального обеспечения внедряются новые подходы, что происходит неравномерно в разных странах. Какие тенденции в администрировании социального обеспечения, «лучшие практики» станут ведущими в будущем? Какой опыт может рассматриваться как пример? Этим вопросам посвящен данный обзор, который может быть интересен для понимания перспектив социального обеспечения и его администрирования.
\end{abstract}

Ключевые слова: социальное обеспечение, администрирование, социальный сервис

\section{Введение.}

Перспективы и пути развития социального обеспечения и страхования находятся в центре экономических и социальных дискуссий последние десятилетия. Наряду с разными взглядами на изменение моделей финансирования и социального распределения в социальном обеспечении, его администрирование пока находится на периферии таких дискуссий. В то же время потенциал администрирования социального обеспечения (АСC) включает помимо сокращения административных расходов другие положительные стороны такие, как предоставление более удобных, качественных и проактивных социальных услуг для граждан с использованием новых технологий. В этой работе мы приводим краткий обзор наиболее выдающихся трендов АСС, которые получат широкое распространение в перспективе. Мы используем данные из открытых интернет источников, как правило, сайтов органов АСС зарубежных стран. Каждый раздел обзора посвящен отдельной тенденции, в заключении мы приводим некоторые выводы. 


\section{1. Интеграция услуг социального обеспечения.}

Одной из ведущих тенденций в администрировании социального обеспечения является предоставление и унификация различных социальных услуг по принципу «одного окна». Оформление и выплата пособий по безработице, пенсий, пособий в связи с материнством, по болезни и других может осуществляться из одного административного центра. Среди стран, которые используют принцип единого центра предоставления социальных услуг и определенные интеграционные процессы в этом направлении: Австралия, Бельгия, Бразилия, Великобритания, Венгрия, Германия, Дания, Индия, Монголия, Норвегия, США, Финляндия, Швеция, Эстония и другие. Формат такого единого центра предусматривает получение социальных услуг по социальному обеспечению, социальному страхованию, услуг по занятости, иногда нотариальных и банковских услуг, других частных услуг в одном месте. Сотрудники разных программ социального обеспечения, управляемых разными социальными учреждениями, предоставляют услуги в одном помещении, как правило, в офисе местного органа власти. Тем самым решается задача получения гражданами качественных и полноценных услуг, в том числе в отдаленных регионах. Объединение услуг по социальной защите, социальному страхованию и занятости в одном месте повышает доступность, удобство, прозрачность оказания таких услуг. Для заявителей это дает экономию времени и денег при доступе к таким услугам. Для учреждений социальной защиты внедрение единых центров обеспечивает снижение административных затрат при объединении процедур подачи заявок и претензий. Благодаря общей отправной точке для всех программ единого центра улучшается также координация между учреждениями, отвечающими за социальную защиту и занятость, одновременно уменьшается дублирование и неэффективность. В целом, единый центр может использоваться для создания общей системы мониторинга и оценки системы социальной защиты и планов местного (муниципального) развития.

Важным и перспективным направлением АCC в рамках единого центра выступает информационная и территориальная близость со службами социальной защиты на региональном уровне. Во-первых, одним из главных факторов в предоставлении социальных и страховых услуг является состояние локального рынка труда и особенностей занятости (безработицы). Концентрация предоставления услуг вокруг такого основного функционала через социальные службы или центры содействия занятости выступает образующим фактором. В-вторых, территориально службы 
социальной защиты регионов (муниципалитетов) представлены почти в каждом населенном пункте. Дополнительно также улучшается вертикальная и горизонтальная координации между разными исполнительными органами в социальном обеспечении: по горизонтали объединяются услуги, например, пенсии, занятость и социальное обеспечение, которые ранее были раздельными, а вертикально создается партнерство между государством, отвечающим за пенсионное обеспечение и службы занятости, и муниципалитетами, отвечающими за социальные помощь и услуги. Социальная защита также может быть поднята на региональный уровень в связи со сложностями ее координации на местном уровне. Между федеральным уровнем и местным самоуправлением предусматривается дополнительная форма взаимодействия: партнерство, в качестве положительного опыта которого приводится пример реформ в Норвегии с созданием национального управления труда и социального обеспечения в качестве основного администратора социального обеспечения в стране путем слияния (взаимодействия) местных администраций на основе служб занятости, национальных страховых администраций и местных служб социальной защиты. Администрация представляет собой соединение центрального агентства и муниципального сервиса и занимается выплатой пособий по безработице, по случаю потери кормильца и инвалидности, пособия по профессиональной травме, национальных страховых пенсий, семейных пособий, нетрудоспособности, материнства, медицинских пособий и других пособий по социальному страхованию. Создание местных офисов национальной администрации было оформлено посредством соглашений о партнерстве между государством как региональным офисом этой администрации и муниципалитетом.

\section{2. Распространение электронных социальных услуг.}

Наряду с интеграционными процессами по предоставлению социальных услуг в сфере социального обеспечения, другой ведущей тенденцией выступает их распространение в электронном: онлайн, дистационном и мобильном форматах. Одним из наглядных примеров, «лучшей практикой» выступают электронные платформы в здравоохранении Финляндии, которые объединяют электронные медицинские карты, лекарственные рецепты и телемедицину. Национальный архив медицинской информации содержит сведения об оказанных медицинских услугах, лечении, исследованиях и медицинских рецептах. Данные пациентов хранятся в медицинских организациях, в которые они обращаются; их раскрытие между разными медицинскими структурами требует согласия пациента. Без такого согласия доступ к медицинским данным, персональной 
электронной медицинской карте могут иметь только службы скорой медицинской помощи. Оформление рецептов на лекарства в электронной форме обеспечивает облегчение и рационализацию назначения и выдачи лекарств. Кроме того, электронная форма рецептов обеспечивает прозрачность оборота лекарств и упрощение подбора методики лечения: система проверяет правильность назначения препарата и его дозировку, используется в качестве справочного пособия для врачей. Реализуемый в стране проект телемедицины предполагает использование так называемых виртуальных домов (порядка тридцати), отвечающих за определенную сферу в медицине: психическое здоровье, контроль веса, артериального давления и другие. Несмотря на невозможность полной замены физического присутствия пациента в медицинском учреждении, виртуальная больница позволяет получать медицинские услуги удаленно в тех случаях, когда не требуется их традиционная форма. Безопасность проведения транзакций в электронном здравоохранении обеспечивается с использованием электронных цифровых подписей, которые используются реже по мере использования электронных услуг, только для входящих или обобщающих документов. Электронные платформы в таком социальном сервисе как медицинские услуги позволяют ускорить процесс приема пациентов, уменьшить врачебные ошибки, сократить расходы на администрирование и упростить такое администрирование, также ускорить возмещение убытков и обеспечить информационную безопасность для медицинских данных. В целом, электронная платформа в сфере здравоохранения может быть эффективно использована для интеграции с другими областями общественного сектора с условием персонификации пользователей. Передовые примеры электронного здравоохранения присутствуют и в остальных странах, например, в Южной Корее, Сингапуре и других.

\section{3. Универсальность индивидуальных социальных счетов.}

Индивидуальные социальные счета для получения услуг социального обеспечения в пенсионном, медицинском страховании или страховании от безработицы, получении социальных пособий достаточно широко применяются в АСС. Персонифицированные социальные счета присутствуют в государственной, корпоративной или индивидуальной формах. Однако пополнение и использование таких социальных счетов, как правило, также определяется государственными, корпоративными или личными ограничениями. В то же время объединение таких социальных счетов на условиях универсальности их использования в АСС имеет преимущества для граждан. Смешанные формы пополнения и использования индивидуальных социальных счетов 
за счет отчислений работодателя и работника, самозанятых лиц, личных накоплений, с учетом государственных пособий для определенных категорий населения (семей с детьми, незанятых, с инвалидностью), налоговых вычетов и льгот позволяют более гибко и функционально реагировать на изменение финансового положения гражданина, использовать средства счетов на приоритетные в данный момент цели: приобретение жилья, единовременные выплаты в случае пополнения семьи и другие. Некоторые аспекты универсальности индивидуальных социальных счетов применяются в АСС в таких странах, как Австралия, Албания, Великобритания, Венгрия, Латвия, Швеция, Эстония и других. При этом расширение универсальности в индивидуальных социальных счетах требует дополнительных действий в сфере доступности электронных услуг, финансовой и цифровой грамотности, доступности интернета.

\section{4. Использование блокчейн и криптовалюты в социальных услугах.}

Одной из перспектив в АСС является использование блокчейн и криптовалюты в социальных услугах. Использование персональной аутентификации при получении государственных социальных услуг в блокчейн платформе позволяет ответить на ряд вызовов неформальной занятости: от подписания контрактов с временными работодателями и заказчиками до регистрации в программах социального обеспечения и уплаты налогов (страховых взносов). Одним из примеров использования таких технологий выступает АСС в Южной Корее. За использование государственных услуг граждане получают определенные баллы, конвертируемые в аналог криптовалюты и ее использование для своих целей: покупок, сервиса. В качестве других стимулов получения криптовалюты определены такие, как использование общественного транспорта для сохранения окружающей среды, экономия использования электроэнергии и воды, раздельный сбор мусора. Подобные технологии в АСС внедряются в Китае, Сингапуре, Японии и других странах. В целом, более прозрачные транзакции со стимулированием социально-значимых действий оплатой криптовалютой позволяют формировать новый тип социальной активности. Одним из примеров измерения такой активности является социальная кредитная система в Китае. Присваиваемый социальный рейтинг с применением систем наблюдения, технологии обработки больших данных и блокчейна позволяет организации в случае высокого социального рейтинга получить преимущества: дополнительные инвестиционные возможности на рынке, налоговые льготы, выгодные условия кредитования, поддержку 
со стороны государственных механизмов стимулирования. Напротив, компании с ненадлежащим социальным рейтингом могут иметь меньшие инвестиционные возможности и другие ограничения. Ожидается, что эти факторы положительно повлияют на экономическое и социальное поведение китайских компаний, в том числе в контексте социального обеспечения и страховых выплат. Кроме того, предполагается, что данный проект будет иметь положительные последствия для реализации программы гармонизации социального обеспечения между городами и сельскими районами, что является одной из задач АСС в Китае.

\section{5. Использование потенциала социального партнерства.}

Социальное партнерство, его продвижение рассматривается как один из вариантов социальной активности коммерческого сектора и волонтерских движений в АСС. Под социальным партнерством мы понимаем участие негосударственных провайдеров социальных услуг в отличие от другой распространенной точки зрения на такое партнерство как социальное движение в борьбе за социальные и трудовые права граждан. Социальное партнерство как подход к оказанию преимущественно государственных социальных услуг в социальном обеспечении с участием некоммерческих и коммерческих организаций в социальном обеспечении позволяет более гибко реагировать на потребности в таких услугах в сфере занятости, социальной помощи, образования, психологической поддержки, юридических консультаций, ухода. В то же время присущие недостатки такого социального партнерства как увеличение финансовой нагрузки на получателей социальных услуг ограничивают в настоящее время его использование.

\section{Заключение.}

Рассмотренные и другие тенденции в современном АСС имеют предпосылки стать ведущими в социальном обеспечении для большинства стран в обозримом будущем. Использование информационно-коммуникационных технологий в социальных услугах позволяет получать такие положительные эффекты, как большая доступность, экономия времени, сокращение бюрократических процедур, автоматизация сбора данных, сокращение административных расходов и многие другие. Важным при этом остается гарантия одинаковых стандартов социальных услуг при переходе к новым формам администрирования в социальном обеспечении. 